\title{
A pliosaurid plesiosaurian from the Rosso Ammonitico Veronese Formation of Italy
}

Andrea Cau and Federico Fanti

Acta Palaeontologica Polonica 59 (3), 2014: 643-650 doi: http://dx.doi.org/10.4202/app.2012.0117

Plesiosauria is a clade of medium to large bodied marine reptiles with a cosmopolitan distribution ranging from the latest Triassic to the end of the Cretaceous. In Europe, the fossil record of Plesiosauria is mainly known from the Northern latitudes, whereas it is much rarer from the Southern and Mediterranean areas. Here, we report the first articulated skeleton of an Italian plesiosaurian, from the Callovian-Oxfordian deposits of the Rosso Ammonitico Veronese Formation of Kaberlaba (Veneto). The specimen is referred to Pliosauridae based on the large size of the skull, compared to the appendicular skeleton, the presence of the lacrimal, and a distinct anterolateral projection of the prefrontal into the orbital margin. Mandibular and vertebral symplesiomorphies support the placement of the Italian taxon among the "gracile-longirostrine grade" of basal pliosaurids. The Kaberlaba plesiosaurian represents the second reptile clade recovered from the Rosso Ammonitico Veronese Formation, after Thalattosuchia.

Key words: Reptilia, Plesiosauria, palaeobiogeography, Rosso Ammonitico Veronese Formation, Callovian-Oxfordian, Italy.

Andrea Cau [cauand@gmail.com], Museo Geologico e Paleontologico'Giovanni Capellini', Alma Mater Studiorum, Università di Bologna, via Zamboni 63, 40126 Bologna, Italy; Federico Fanti [federico.fanti@unibo.it], Dipartimento di Scienze Biologiche, Geologiche e Ambientali, Alma Mater Studiorum, Università di Bologna. Via Zamboni 67,40126 Bologna, Italy.

This is an open-access article distributed under the terms of the Creative Commons Attribution License (for details please see creativecommons.org), which permits unrestricted use, distribution, and reproduction in any medium, provided the original author and source are credited. 
Farf Full text $(722.4 \mathrm{kB})$

For's Supplementary file $(18.7 \mathrm{kB})$ 